Research, Society and Development, v. 9, n. 4, e139942985, 2020

(CC BY 4.0) | ISSN 2525-3409 | DOI: http://dx.doi.org/10.33448/rsd-v9i4.2985

\title{
Gestão escolar democrática: dimensão diretiva aos processos educacionais significativos
}

\section{Democratic school management: directive dimension to significant educational processes}

Gestión escolar democrática: dimensión directiva para procesos educativos significativos

Recebido: 02/03/2020 | Revisado: 03/03/2020 | Aceito: 11/03/2020 | Publicado: 21/03/2020

\section{Sandra Maria Campos Alves}

ORCID: https://orcid.org/0000-0002-9343-9324

Instituto Federal de Educação, Ciência e Tecnologia do Rio Grande do Norte, Brasil

E-mail: sandra.campos@ifrn.edu.br

Mara Renata Barros Barbosa

ORCID: https://orcid.org/0000-0003-1556-5832

Instituto Federal de Educação, Ciência e Tecnologia do Rio Grande do Norte, Brasil

E-mail: mararenata7@gmail.com

\section{Resumo}

O presente artigo disserta sobre a importância de ações significativas e colaborativas para o avanço dos processos educativos no ambiente escolar, no contexto da gestão escolar democrática. O objetivo deste estudo é refletir sobre a importância da gestão escolar democrática como ponto de partida para que as ideias de planejamento, organização e envolvimento de atores sociais fortaleça a busca por transformações propositivas e positivas na qualidade do ensinar-aprender. Como metodologia utilizou-se a pesquisa bibliográfica para a análise dessa temática tomando como referência a abordagem qualitativa que promove breves considerações acerca da relevância da gestão escolar no campo educacional, bem como sobre a importância da construção coletiva democrática das decisões da organização escola. Desse modo, os instrumentos foram livros, artigos periódicos e leis para esta pesquisa de cunho qualitativo. Os resultados evidenciam que repensar as práticas educativas, o planejamento, a organização e o envolvimento de atores sociais numa elaboração conjunta, fomenta mecanismos favorecedores de melhorias na formação educativa de qualidade e lhes dá sentido. Conclui-se que a pesquisa permitiu a percepção de que a gestão escolar democrática escolar é um ponto fulcral na formação da educação para a democracia, sob um aspecto solidário e integrador.

Palavras-chave: Gestão escolar democrática; Processos educativos; Construção coletiva. 


\section{Abstract}

This article discusses the importance of meaningful and collaborative actions for the advancement of educational processes in the school environment, in the context of democratic school management. The aim of this study is to reflect on the importance of democratic school management as a starting point for the ideas of planning, organization and involvement of social actors to strengthen the search for positive and positive transformations in the quality of teaching-learning. As a methodology, bibliographic research was used to analyze this theme, taking as a reference the qualitative approach that promotes brief considerations about the relevance of school management in the educational field, as well as about the importance of the collective democratic construction of school organization decisions. Thus, the instruments were books, periodical articles and laws for this qualitative research. The results show that rethinking educational practices, planning, organization and the involvement of social actors in joint development, fosters mechanisms that favor improvements in quality educational training and gives them meaning. It is concluded that the research allowed the perception that democratic school management in schools is a central point in the formation of education for democracy, under a solidary and integrating aspect.

Keywords: Democratic school management; Educational processes; Collective construction.

\section{Resumen}

Este artículo analiza la importancia de acciones significativas y de colaboración para el avance de los procesos educativos en el entorno escolar, en el contexto de la gestión escolar democrática. El objetivo de este estudio es reflexionar sobre la importancia de la gestión escolar democrática como punto de partida para las ideas de planificación, organización e implicación de los actores sociales, a fin de fortalecer la búsqueda de transformaciones positivas y positivas en la calidad de la enseñanza y el aprendizaje. Como metodología, se utilizó la investigación bibliográfica para analizar este tema, teniendo como referencia el enfoque cualitativo que promueve breves consideraciones sobre la relevancia de la gestión escolar en el campo educativo, así como sobre la importancia de la construcción colectiva democrática de las decisiones de la organización escolar. Así, los instrumentos fueron libros, artículos periódicos y leyes para esta investigación cualitativa. Los resultados muestran que repensar las prácticas educativas, la planificación, la organización y la participación de los actores sociales en el desarrollo conjunto, promueve mecanismos que favorecen la mejora de la calidad de la educación y les dan sentido. Se concluye que la investigación permitió darse cuenta de que la gestión escolar democrática en las escuelas es un punto central en la formación de la educación para la democracia, bajo un aspecto solidario e integrador.

Palabras clave: Gestión escolar democrática; Procesos educativos; Construcción colectiva. 


\section{Introdução}

As instituições educativas têm responsabilidades sociais no que diz respeito à promoção dos processos de aprendizagem, realizando funções que nenhuma outra instituição promove. Nos espaços escolares, a formação geral básica é promovida levando-se em conta o aprimoramento científico, ético e cognitivo dos sujeitos. Sabe-se que não são os únicos lugares de construção do saber, visto que este se faz em diversos espaços e situações.

Enquanto espaço destinado aos processos de ensino-aprendizagem, existe a necessidade de que a estrutura organizacional e pedagógica da escola seja efetivamente planejada, para que os processos educativos de qualidade de fato tornem-se realidade. Tal qualidade é produto dos objetivos que se pretende alcançar com a educação. Se o objetivo for a formação da educação para a democracia, tem-se na gestão democrática escolar, um ponto fulcral no início deste processo. Para Lück (2009, p.70)

A democracia constitui-se em característica fundamental de sociedades e grupos centrados na prática dos direitos humanos por reconhecerem não apenas o direito de as pessoas usufruírem dos bens e serviços produzidos em seu contexto, mas também, e sobretudo, seu direito e seu dever de assumirem responsabilidade pela produção e melhoria desses bens e serviços. Com essa perspectiva, direitos e deveres são dois conceitos indissociáveis, de modo que, falando-se de um, remetese ao outro necessariamente. E é nessa junção que se estabelece a verdadeira democracia, construída mediante participação qualificada pela cidadania e construção do bem comum.

A democracia denota participação, construção coletiva, representando a ideia de prática social, o que deve ser algo permanente na escola. Vivenciando processos participativos, a comunidade escolar vai aprendendo a se tornar mais responsável por decisões que a engloba não apenas no ambiente da escola, mas numa escala mais ampla que é a sociedade. Compartilham-se conhecimentos, valores, capacidades e competências para a participação no mundo socioeconômico e também cultural.

[...] a democracia efetiva traz a possibilidade de compreensão crítica da realidade, contribuindo para a inovação, para a construção coletiva e para o sentimento de pertença, bem como para a manutenção ou transformação da ordem social. Nesse sentido, a democracia efetiva contribui tanto para o crescimento individual como coletivo e institucional. [...] (Escott,2015, p.24)

Este formato de gestão na escola, é o ponto de partida para o conhecimento do que vem a ser democrático, um constructo participativo em que os sujeitos se entendem como cidadãos que podem e devem opinar/colaborar com o processo educativo do qual fazem parte. A percepção de agentes e não meros coadjuvantes, faz destes atores sociais, seres dotados de 
autonomia, numa elaboração conjunta de mecanismos favorecedores de melhorias na formação educativa de qualidade. Esta autonomia é capaz de, na partilha de objetivos, valorizar a possibilidade de repensar as práticas educativas, indicar caminhos alternativos, potencializando o que já existe e ressignificando a ideia de integração.

Neste processo que é desenvolvido em constância, é preciso considerar a heterogeneidade de raciocínios, buscando um denominador comum, a qualidade da Educação. Haverá conflitos de interesses por vezes, porém, atentando-se para o fator responsabilidade, estes vão sendo redimensionados visando a integração da comunidade escolar. "Enfim, é como a democracia que é tecida no interior da escola, e ela nem sempre será linearmente praticada, nem sempre será sem conflitos. Ou seja, está sendo construído o aprendizado da democracia, e esta será desenvolvida como uma prática constante.” (Kimura, 2008, p.42)

Para que as ações coletivas sejam fortalecidas, necessário se faz revitalizar a importância da escola enquanto espaço de socialização, visando a construção do conhecimento. Numa gestão colegiada, é fundamental que todos tenham espaço atuante, com propósitos claros em que a educação e a formação cidadã sejam bases. Referimo-nos aqui a uma escola inclusiva que alcance a todos e a todas. "A educação inclusiva pode ser definida como a prática de inclusão de todos- independentemente de seu talento, deficiência, origem socioeconômica ou cultural- em escolas e salas de aula provedoras, onde as necessidades desses alunos sejam satisfeitas." (Stainback \& Stainback;1999, p.21)

Ao mencionarmos educação de qualidade, estamos apontando para uma educação libertadora que emancipe os sujeitos, para que sejam crítico-reflexivos de sua realidade e tenham em mente a prática da participação transformadora. A escola pode favorecer a formação de valores e práticas éticas em seu alunado, com vistas a capacitá-los para exercer sua cidadania na construção de uma sociedade com mais justiça e menos desigualdades sociais.

[...] as escolas de qualidade são espaços educativos de construção de personalidades humanas autônomas, críticas, espaços onde crianças e jovens aprendem a ser pessoas. Nesses ambientes educativos, ensinam-se os alunos a valorizar a diferença pela convivência com seus pares, pelo exemplo dos professores, pelo ensino ministrado nas salas de aula, pelo clima sócio-afetivo das relações estabelecidas em toda a comunidade escolar- sem tensões competitivas, mas com espírito solidário, participativo. Escolas assim concebidas não excluem nenhum aluno de suas classes, de seus programas, de suas aulas, das atividades e do convívio escolar mais amplo. [...] (Mantoan, 2003, p.35)

Neste âmbito, as reflexões contidas neste trabalho pretendem ampliar a discussão sobre a importância da gestão escolar democrática como desencadeadora de processos democráticos, logo no ambiente escolar. Entendemos que ao permitirem-se ações e interações 
sob a perspectiva da colaboração conjunta, estas terão significações e positivas repercussões na vida do sujeito em sua prática pessoal e social. Intentamos, pois, também intensificar o debate acerca da gestão escolar democrática, como importante ferramenta organizativa de articulação de atividades e decisões necessárias ao funcionamento da escola de forma integradora.

A importância destes apontamentos está em entender a educação escolar como promotora de saberes procedimentais e atitudinais, tendo a função social de desenvolver amplas capacidades. Estando imersa na ideia de democracia plena, formará não apenas aprendentes, mas cidadãos participativos e éticos, muito necessários às transformações de mundo que vivenciamos e precisamos.

O objetivo deste estudo é refletir sobre a importância da gestão escolar democrática como ponto de partida para que as ideias de planejamento, organização e envolvimento de atores sociais fortaleça a busca por transformações propositivas e positivas na qualidade do ensinar-aprender. Desta forma, a seguir discutiremos um pouco mais sobre a Gestão democrática na escola e processos educacionais significativos advindos a partir desta.

\section{Metodologia}

A pesquisa constitui-se de análise bibliográfica de tipo qualitativo. Este estudo é especificamente de análises de referenciais de revisão bibliográfica. A pesquisa qualitativa objetiva qualificar o tema pesquisado sobre Gestão democrática nos espaços escolares, buscando fontes que versem sobre esta temática. Para Flick(2013, p.93-94)

$\mathrm{Na}$ pesquisa qualitativa [...] os estudos podem estar relacionados a trabalhos teóricos e empíricos anteriores sobre o tema em questão. O estado atual da pesquisa existente deve influenciar seus procedimentos metodológicos e empíricos subsequentes. Na pesquisa qualitativa pode haver várias possibilidades de estruturas para o estudo de uma questão

Para a coleta das fontes, utilizou-se como critério livros, artigos de periódicos e leis, que versassem sobre a temática desta pesquisa, utilizando as seguintes palavras-chave: Gestão escolar democrática, Processos educativos, Construção coletiva. 


\section{Gestão Democrática na Escola}

A importância de ações para os avanços dos processos de ensino-aprendizagem no ambiente educacional fomentou importantes discussões acerca de reformas neste contexto. Esse foi o ponto de partida para que as ideias de planejamento, organização e envolvimento de atores sociais fortalecesse a busca por transformações propositivas e positivas na qualidade do ensinar-aprender, a busca por gestão escolar. Para complementar nossas reflexões Lück $(2009$, p.24) aponta que

Gestão escolar é o ato de gerir a dinâmica cultural da escola, afinado com as diretrizes e políticas educacionais públicas para a implementação de seu projeto político-pedagógico e compromissado com os princípios da democracia e com os métodos que organizem e criem condições para um ambiente educacional autônomo (soluções próprias, no âmbito de suas competências), de participação e compartilhamento (tomada de decisões conjunta e efetivação de resultados e autocontrole (acompanhamento e avaliação com retorno de informações).

O dinamismo da escola deve levar em consideração as políticas educacionais, seu PPP (Projeto Político Pedagógico) e as condições sociais nas quais está inserida, para que os direcionamentos político-pedagógicos sejam desenvolvidos por ações conjuntas e em articulação. Para Libâneo (2007, p.15-16)

A importância da gestão educacional de sistemas de ensino e escolas tem sido ressaltada há anos na pesquisa educacional, tendo sido, inclusive, antecipada nas propostas pedagógicas de esquerda. É notório que a autonomia fortalece as escolas, acentua o espírito de equipe, envolvendo os professores e demais educadores na responsabilidade em assumir um papel na configuração da organização do trabalho escolar não apenas na sala de aula, mas na escola como um todo. Trata-se de um processo que se identifica bem com a reivindicação de participação conjunta de pais, professores, alunos, nos processos de tomada de decisão e coresponsabilização pelas ações de ensino-aprendizagem.

De fato, em diversas pesquisas educacionais ressalta-se a imprescindibilidade da gestão dos ambientes escolares, haja visto o caráter sistêmico da função social da escola. A variedade de sujeitos envolvidos na educação denota a ideia de coletividade, como peças de um grande quebra-cabeças. Cada qual com uma função específica e que articuladas compõem o todo. Para Cortella (2014 a, p. 41):

O trabalho de Educação é coletivo, é feito com as pessoas. É esse ato coletivo que nos coloca o imperativo de nos desenvolvermos coletivamente também. E, para isso, é preciso acreditar em dois grandes princípios: Quem sabe reparte e quem não sabe procura! Porque se aquele que sabe não repartir, enfraquece aos outros e a si mesmo. E se aquele que não sabe não procurar, enfraquece a si mesmo e o local onde está. Nessa hora, a noção de parceria fica fortalecida.(Grifos do autor) 
Research, Society and Development, v. 9, n. 4, e139942985, 2020

(CC BY 4.0) | ISSN 2525-3409 | DOI: http://dx.doi.org/10.33448/rsd-v9i4.2985

É exatamente nesse sentido de conjunto, que baseamos nossas reflexões sobre a gestão democrática na escola, é de fato um trabalho feito com muitas pessoas, em que o desenvolvimento deve ser recíproco entre estas e o local onde atuam. De forma simples, baseando-nos no que diz Cortella, é preciso que o saber seja repartido e aquele que não sabe busque e possa encontrar a disponibilidade de ser ajudado. Se assim não o for, o trabalho de equipe não avança, e infelizmente isso ainda é comum em variados espaços educativos.

A gestão escolar é responsável pelos encaixes de ações adequados, em que todos são atuantes e necessários. Para que o todo possa se compor, a gestão precisa de estratégias como a descentralização de serviços, autonomia, dialogicidade, participação, enfim, ações didático-pedagógicas que envolvam a todos em união. Contribuindo com nossas reflexões, Boschetti \& Mota e Abreu (2016, p.104) nos apresentam de forma sintética a função da gestão escolar:

O processo de gestão escolar tem como função primordial a descentralização do desenvolvimento pedagógico e administrativo no sistema de ensino. O resultado desse gerenciamento é a crescente autonomia da escola diante do compromisso e envolvimento de todos os atores que participam dessa construção democrática. Portanto, o processo de gestão evoca também vários indicadores a serem trabalhados, tais como a gestão participativa, relações interpessoais, desempenho e auto avaliação.

As autoras acima mencionadas, citam a importância da descentralização, a gestão não mais direcionada na figura de um (a) gestor (a) apenas, mas dividida entre os atores do espaço educativo. Nas mãos de todos e todos de mãos dadas, uma representação da construção da democracia no ambiente de educação formal, a escola. A gestão democrática neste espaço é de grande valor, não penas por gerir e organizar as atividades educacionais, mas por estimular as inter-relações de sujeitos diversos através da cultura participativa. $\mathrm{O}$ ser que se sente parte e não à parte de um processo, sente a incumbência da responsabilidade de colaborar com o todo, porque ele também se utiliza daquele espaço e dos serviços ali ofertados.

Desta maneira, entende-se que "o grau de importância atribuído às formas de organização e gestão depende de objetivos sociais e pedagógicos que propõem à escola os quais, por sua vez, subordinam-se a concepções sobre as relações educação-sociedade" (Libâneo,2007, p.16). Organizar-se-ão as atividades de acordo com as necessidades de cada contexto escolar, estruturalmente, de PPP, dos objetivos didático-pedagógicos que se almejam alcançar.É desta forma que a gestão tem o ponto de partida para então iniciar a execução de suas ações. Na LDB-9394/96 o artigo 14 estabelece que, 
Research, Society and Development, v. 9, n. 4, e139942985, 2020

(CC BY 4.0) | ISSN 2525-3409 | DOI: http://dx.doi.org/10.33448/rsd-v9i4.2985

Os sistemas de ensino definirão as normas da gestão democrática de ensino público na educação básica, de acordo com as suas peculiaridades e conforme os seguintes princípios:

I -Participação dos profissionais da educação na elaboração do projeto políticopedagógico da escola;

II-Participação das comunidades escolar e local em conselhos escolares ou equivalentes.

Considerar-se-á a importância de uma gestão, se as finalidades desta estiverem em consonância sócio pedagógica entre escola e sociedade. A significação da gestão da escola é muito abrangente, pois

[...] a gestão educacional tem natureza e características próprias, ou seja, tem escopo mais amplo do que a mera aplicação dos métodos, técnicas e princípios da administração empresarial, devido à sua especificidade e aos fins a serem alcançados. Ou seja, a escola, entendida como instituição social, tem sua lógica organizativa e suas finalidades demarcadas pelos fins político-pedagógicos que extrapolam o horizonte custo-benefício stricto sensu. Isto tem impacto direto no que se entende por planejamento e desenvolvimento da educação e da escola e, nessa perspectiva, implica aprofundamento sobre a natureza das instituições educativas e suas finalidades, bem com as prioridades institucionais, os processos de participação e decisão, em âmbito nacional, nos sistemas de ensino e nas escolas. (Dourado, 2007, p. 924)

A gestão escolar não se reduz a questões de burocracia e administração, são mais que tudo, práticas educacionais. Práticas estas que envolvem valores, ações, percepções e que produzem aprendizagens para além dos muros físicos, produzem aprendizados sociais. Não é algo pronto e acabado para executar, muito pelo contrário, é único e por envolver diferentes sujeitos se torna muito desafiador. Complementando nosso raciocínio a este respeito, Marques (2006, p.513) entende que

Desta forma, a gestão democrática de escolas públicas pode ser incluída no rol de práticas sociais que podem contribuir para a consciência democrática e a participação popular e, portanto, para a democratização da própria sociedade. $\mathrm{O}$ estudo da democracia na gestão de escolas públicas pode, portanto, contribuir para o entendimento da democratização da sociedade, na medida em que busca esclarecer como mudanças geradas pelas políticas de democratização sobre ela repercutem.

Estas ponderações sintetizam bem o objetivo principal deste artigo, a gestão democrática nas escolas, principalmente públicas, são a base das práticas sociais que levam ao pensamento e ações democráticas. Ações e pensamentos que ultrapassam os espaços materiais de uma escola, que seguem estrada à fora por vários lugares onde a sociedade se estenda. Conhecer a democracia na prática é empoderar os sujeitos a agir em consonância com o bem coletivo, auxilia-o a pensar globalmente a importância de valorizar a coisa pública. 
Sendo a escola um espaço educativo, todos os envolvidos aprendem constantemente. A gestão democrática na escola é mais uma forma do conhecer, é participar com o outro, é a democracia em prática, indispensável na formação de cidadãos. Colaborando com nossas reflexões, Santomé (2001, p.51) nos diz que

É imprescindível comprometer-se na tarefa comunitária de democratizar as instituições escolares, tanto no desempenho dos postos de trabalho, como na construção, desenvolvimento e avaliação dos projetos curriculares executados. É convenente que a autonomia seja estabelecida a partir de um discurso mais inclusivo, capaz de reunir a fala de todas as pessoas que convivem e trabalham nas escolas. Autonomia para a instituição, não para que determinado coletivo possa impor suas ideias e projetos aos demais, sem a necessidade de debater e de convencer os que também serão afetados: os alunos, as alunas, suas famílias e a comunidade.

O autor nos fala sobre o compromisso que devemos assumir em democratizar as instituições escolares, em todas as atividades que nelas houver. Versa também que sobre a implantação da autonomia que advém da participação coletiva através de ideias e projetos, sem imposições, mas refletida em conjunto. A necessidade do debate é fundamental na tomada de decisões, pois seus benefícios e/ou consequências envolve a todos. Construir coletivamente é democratizar a participação, é desenvolver o senso crítico-reflexivo através de ações solidárias e responsáveis.

[...] Desta maneira, recupera-se para as instituições de ensino sua verdadeira razão de ser, a de espaços onde se aprende a ser cidadã e cidadão, a analisar informada e criticamente o que está ocorrendo na sociedade, a criar disposições e atitudes positivas de colaboração e participação nas resoluções de problemas coletivos. (Santomé, 2001, p.54)

O aprendizado pode ser comparado a galhos, que pertencem à mesma árvore, são alimentados pela seiva de seu tronco, essa árvore chamamos de Educação. Do mesmo modo entendamos a função que a escola tem em manter essa árvore com vida, se desenvolvendo, os galhos criando folhas, flores, frutos. É preciso saber o que acontece ao redor desta árvore, o que é preciso para mantê-la forte e saudável, esse seria o papel da gestão. Perceber como essa árvore cresce, o seu tipo, o solo que mais se adequa, a matéria orgânica, o clima, enfim. Tomamos este exemplo para podermos fazer uma analogia com a gestão escolar democrática, mas principalmente entender suas funções e importância.

O potencial democrático da gestão escolar é fundamental para que todos nos alimentemos e fiquemos à sombra da árvore da Educação. Concordamos com Cortella (2014b, p.92) ao refletir que “ Na democracia é preciso ouvir, prestar atenção, dispor-se ao envolvimento, recusar a passividade, rejeitar a conivência e acolher a decisão da maioria. A 
democracia educa a nossa convivência e, mais do que tudo, permite que sejam renovadas as nossas utopias".

A prática da democracia já na escola, incute nos sujeitos a importância do respeito ao outro, da necessidade de pensar e atuar coletivamente e de con(viver). Inspira a luta conjunta por tempos sempre melhores no porvir, nem que seja utopicamente, batalha-se pelo bem estar de todos.

Há, sem dúvidas, intempéries neste processo, obstáculos a serem superados para promover mudanças importantes no sistema escolar e na vida em sociedade. Diante dessas perspectivas, objetivar o melhor para a educação é sempre o caminho mais acertado para que o processo educativo seja significativo. A este respeito discutiremos um pouco mais no tópico a seguir.

\section{Processos Educacionais Significativos e Gestão Escolar}

A escola na sua função social, tem um papel fundamental na compreensão do aporte democrático porque

[...] é um meio insubstituível de contribuição para as lutas democráticas, na medida em que possibilita às classes populares ao terem o acesso ao saber sistematizado e às condições de aperfeiçoamento das potencialidades intelectuais, participarem ativamente do processo político, sindical e cultural (Libâneo,2013, p.39)

Contribui com a democracia ao fornecer o saber sistemático e a incumbência de auxiliar no desenvolvimento cognitivo dos sujeitos, estimulando-os a compreender o meio em que vivem, articulando saberes a vivências. É através da prática educativa intencional que o objetivo de formar indivíduos capacitados para lutar por direitos e transformar para melhor a sua sociedade, é possível. Corroboramos com Marques (2006, p.510) ao apontar que

Cumpre considerar, contudo que a discussão sobre a democratização da gestão escolar é uma demanda antiga de pesquisadores e trabalhadores da área, defendida por estes como um dos mecanismos importantes para se alcançar uma educação pública de qualidade, universal, como exercício de cidadania. Dessa forma, mesmo sendo implantada com base nos princípios neoliberais, a gestão democrática no sistema educacional público abre possibilidades para que se construa uma escola pública de qualidade, que atenda aos interesses da maioria da população brasileira, além de representar uma possibilidade de vivência e aprendizado da democracia, podendo, portanto, tomar um sentido diferenciado do proposto pelos fazedores de política. Nessa perspectiva, e admitindo o movimento dialético da história, podemos considerar que a implantação de novas diretrizes da política educacional nas escolas não está, em princípio, predeterminada, podendo, portanto, tomar sentidos diferenciados. 
A educação pública, para que seja de qualidade, tem na democracia um dos pilares de sua efetivação. Embora estejamos num contexto neoliberal, lembrado pela autora, ainda nesses moldes, a população do nosso país precisa de uma educação libertadora que estimule o indivíduo a pensar de forma crítico-reflexiva.

A criticidade é desenvolvida pelo estímulo ao raciocínio, à investigação. Para tanto é preciso fomentar a sensibilidade ao que é coletivo, solidário, cooperativo. A visão de conjunto do trabalho escolar forma o indivíduo social e o prepara para a vida. Concordamos com Lück (2009, p.24) ao inferir que

A gestão escolar constitui uma dimensão e um enfoque de atuação em educação, que objetiva promover a organização, a mobilização e a articulação de todas as condições materiais e humanas necessárias para garantir o avanço dos processos socioeducacionais dos estabelecimentos de ensino, orientados para a promoção efetiva da aprendizagem dos alunos, de modo a torná-los capazes de enfrentar adequadamente os desafios da sociedade complexa, globalizada e da economia centrada no conhecimento. Por efetividade entende-se, pois, a realização de objetivos avançados, em acordo com as novas necessidades de transformação socioeconômico-cultural, mediante a dinamização do talento humano, sinergicamente organizado.

De fato, sua função organizativa de estrutura e sujeitos favorece $o$ desenvolvimento educativo e social não só dos alunos- foco principal da ação educativa- mas de todos que compõem a categoria escola. É através da experiência que as memórias se condensam e se tornam conhecimento. Em um mundo tão heterogêneo em que o conhecimento é a engrenagem mestra, ser coparticipante da gestão do aprender é um diferencial valioso. É nesse sentido que mencionamos os processos educativos significativos, que dotados de sentido tem aplicabilidade prática e real.

A aprendizagem será muito mais significativa na medida em que o novo material for incorporado às estruturas de conhecimento de um aluno e adquirir significado para ele, a partir da relação com o seu conhecimento prévio. Ao contrário, será mais mecânica ou repetitiva na medida em que se produzir menos essa incorporação e atribuição de significado, e o novo material será armazenado isoladamente ou por meio de associações arbitrárias na estrutura cognitiva. (Salvador, 2000, p.232)

$\mathrm{O}$ autor acima referenciado, dirige-se à aprendizagem significativa do aluno público-alvo da escola-, porém levemos esse pensamento a todos os sujeitos da gestão escolar. Como ele afirma, a aprendizagem será significativa se para o sujeito ela tiver algum sentido que se relacione com o já conhecido.

À medida que vai incorporando novos saberes, estes vão sendo armazenados na sua cognição. O que aqui queremos destacar, é que para um saber se tornar parte de alguém, esse saber precisa ser importante, útil e transformador. Estamos de acordo com Freire (2015, 
p.29), que "[...], no processo de aprendizagem, só aprende verdadeiramente aquele que se apropria do aprendido, transformando-o em apreendido, com o que pode, por isso mesmo, reinventá-lo; aquele que é capaz de aplicar o aprendido-apreendido em situações existenciais concretas."

O ser que aprende e aplica o aprendido, que percebe esta aplicabilidade em sua prática sócio-política, compreende a importância do conhecimento. Sente-se um agente e não apenas um receptáculo de informações, torna-se um ser capaz de transformar e reinventar seus saberes em sua prática cotidiana

O acesso democrático ao conhecimento sistematizado que a escola oferece é um direito social tanto individual quanto coletivo. É a travessia para a formação de seres humanos que lutem por igualdade e solidariedade. A busca de um futuro melhor começa no hoje, no processo de construção de saberes com a escola, com o sistema educacional, com a família e a sociedade da qual faz parte. A construção coletiva de atitudes, valores e saberes estruturam práticas sociais transformadoras, includentes e resistentes a exclusões. Enriquecendo nossos apontamentos, Freire (2015, p.30) explica que

[...] o homem, que não pode ser compreendido fora de suas relações com o mundo, de vez que é um "ser-em-situação", é também um ser do trabalho e da transformação do mundo. O homem é um ser da " práxis"; da ação e da reflexão. (Grifos do autor)

Nós somos parte do todo, nossas inter-relações são imprescindíveis, através de nosso trabalho, modificamos o espaço sócio interacional do qual fazemos parte. Refletimos e agimos.

A perspectiva de um futuro de esperança precisa de esforços que redefinam a educação escolar, a educação geral formal e não formal. A escola é uma potência criadora, é importante reconhecê-la como tal e colaborar para que seus pressupostos sejam significativos a projetos diversos de sociedade e educação.

É justamente nesse sentido que a conclusão se faz recomeço por procurar pistas já inscritas e por inscreverem-se nas superfícies da educação escolar, feita de tantas tendências em embate. Um convite para juntos abrirmos e conectarmos caminhos por onde possam transitar saberes que afirmem a vida, com toda sua busca de aperfeiçoamento e solidariedade (Linhares, 2001, p.170)

A educação escolar não é apenas a da prática conteudista, mas um cerne da educação ampla que forma o ser sapiente, mas também pode- e deve- formar o ser sensível aos seus contextos individual e coletivo. Os significados abrem caminhos para as ressignificações, para a quebra de paradigmas excludentes, que separam. Juntos podemos 
traçar trajetos que como disse a autora acima " afirmem a vida", que em conjunto, mesmo com nossas individualidades possamos ser unidade.

\section{Considerações Finais}

A gestão escolar democrática é geratriz de um constructo participativo, imerso de reponsabilidades sociais. Democratizar as instituições escolares é promover um potencial de senso crítico-reflexivo de ações solidárias.

O caráter sistêmico das funções sociais da escola, inspira ideais de integração. Faz repensar as práticas educativas, o planejamento, a organização e o envolvimento de atores sociais. Tal elaboração conjunta, fomenta mecanismos favorecedores de melhorias na formação educativa de qualidade e lhes dá sentido.

Mediante o objetivo inicial deste estudo conseguimos alcançar o intento de refletir sobre a importância da gestão escolar democrática como ponto de partida para que as ideias de planejamento, organização e envolvimento de atores sociais fortaleça a busca por transformações propositivas e positivas na qualidade do ensinar-aprender. Compreendemos as limitações destas reflexões, este trabalho não tem pretensão de ser o norte único das práticas renovadoras da gestão democrática escolar mas certamente pode ser um meio de pesquisa, uma opção didática ou material que desperte nos pesquisadores, alunos, docentes e comunidade científica discussões e reflexões. Para futuras abordagens sobre o tema, sugerimos um estudo de caso em um ambiente escolar, em que efetivamente ocorram práticas democráticas.

A escola é potência criadora, a gestão democrática desta, alicerça a perspectiva de um futuro de esperança, repleto de uma amplitude de significações, de sentidos e apreensões. É apenas um dos caminhos que o processo educativo se mune para que a educação tenha forma e forme. Faz-se necessário que a coloquemos em lugar de destaque nos ambientes escolares, pois é esta que faz o processo educativo qualitativo.

Todos têm direito a uma boa educação, que seja base sólida para que se participe da vida social e cultural de forma crítico-reflexiva. É pela educação que somos preparados e convocados a melhorar nossa realidade.

Não sejamos ingênuos de afirmar ser este um processo simples e concêntrico, ele é sistêmico e inter-relacional. Daí nossa colaboração em colocar mais uma vez em debate a importância da efetivação da gestão democrática nos ambientes escolares de formação cidadã. 
A soma das partes é muito maior que o todo, somos ramificações de um quadro educativo que precisa de proposições rápidas e principalmente eficazes. Estejamos, pois, imbuídos do interesse de promover a qualidade do processo educacionais para que tenham sempre ressignificações. Que sejamos união pelo bem maior da formação humana que é a Educação.

\section{Referências}

Boschetti, Vania Regina; Mota, Assislene Barros da; Abreu, Dayse Lúcide de Freitas. (2016). Gestão escolar democrática: desafios e perspectivas. Revista de gestão e avaliação educacional, 5(10), jul./dez. 103-111. Disponível em http://dx.doi.org/10.5902/2318133822257. Acesso em: 22 abr.2019.

Brasil. Constituição (1998). Lei de Diretrizes e Bases da Educação Nacional, n. 9.394, de 20 de dezembro de 1996. Disponível em< http://www.mec.gov.br>. Acesso em: 25 mai.2019.

Cortella, Mario Sergio. (2014a). Educação, escola e docência: novos tempos, novas atitudes. São Paulo: Cortez.

Cortella, Mario Sergio. (2014b). Pensatas pedagógicas: nós e a escola: agonias e alegrias. Petrópolis: Vozes.

Dourado, Luiz Fernandes. (2007). Políticas e gestão da educação básica no Brasil: limites e perspectivas. Revista Educação \& Sociedade, 28(100), 921-946.Disponível em http://dx.doi.org/10.1590/S0101-73302007000300014. Acesso em: 22 abr.2019.

Escott, Clarice Monteiro. (2015). A participação como indicador de inclusão social na educação superior. Revista de Educação do COGEIME, 24(46), 15-27.

Flick, Uwe. (2013). Introdução à metodologia de pesquisa: um guia para iniciantes. Tradução de Magda Lopes. Porto Alegre: Penso.

Freire, Paulo. (2015). Extensão ou comunicação? Tradução de Rosiska Darcy de Oliveira.17. ed. São Paulo: Paz e Terra. 
Kimura, Shoko. (2008). Geografia no Ensino Básico: questões e propostas. São Paulo: Contexto.

Libâneo, José Carlos. (2007). Concepções e práticas de organização e gestão da escola: considerações introdutórias para um exame crítico da discussão atual no Brasil. Revista Española de Educación Comparada, 13,155-191.

Libâneo, José Carlos. (2008). Organização e gestão da escola: teoria e prática. Goiânia: MF Livros.

Libâneo, José Carlos. (2013). Didática. São Paulo: Cortez.

Linhares, Célia (Org.). (2001). Os professores e a reinvenção da escola: Brasil e Espanha. São Paulo: Cortez.

Lück, Heloísa. (2009). Dimensões de gestão escolar e suas competências. Curitiba: Editora Positivo.

Mantoan, Maria Teresa Eglér. (2003). Inclusão escolar: O que é? Por quê? Como fazer? São Paulo: Moderna.

Marques, Luciana Rosa. (2006). Caminhos da democracia nas políticas de descentralização da gestão escolar. Ensaio: avaliação em políticas públicas em educação,14(53), 507-526.

Salvador, César Cool. Psicologia do ensino. (2000). Tradução de Cristina Maria de Oliveira. Porto Alegre: Artes Médicas Sul.

Santomé, Jurjo Torres. O professorado em época de neoliberalismo: dimensões sociopolíticas de seu trabalho.In: Linhares, Célia (Org.).(2001).Os professores e a reinvenção da escola: Brasil e Espanha. São Paulo: Cortez.

Stainback, S.; Stainback, W. (1999). Inclusão: um guia para educadores. Porto Alegre: Artmed. 


\section{Porcentagem de contribuição de cada autor no manuscrito}

Nome do primeiro autor centralizado $-50 \%$

Nome do segundo autor centralizado $-50 \%$ 